\title{
Ego Depletion and Time Pressure Promote Spontaneous Deception: An Event-Related Potential Study
}

\author{
Wei Fan ${ }^{1,2}$, Ying Yang 1,2, Wenjie Zhang 1, , and Yiping Zhong ${ }^{1,2}$ \\ Cognition and Human Behavior Key Laboratory of Hunan Province, Hunan Normal University, Changsha, 410081, China \\ 2 Department of Psychology, School of Education Science, Hunan Normal University, Changsha 410081, China \\ ${ }^{3}$ Department of Preschool Education, School of Education Science, Hunan Normal University, Changsha 410081, China
}

\section{KEYWORDS}

ego depletion

time pressure

deception

P3 amplitude
ABSTRACT

Event-related potentials (ERPs) were used to explore the influence of ego depletion on spontaneous deception under time pressure. The Stroop Color-Word test was used to manipulate the participants' ego depletion in the experiment. A visual perception task was employed to assess the participants' deceptive tendency. The results indicated that the ego-depleted group was more prone to engaging deception and induced a larger $\mathrm{P} 3$ amplitude than did the nondepleted group. The no-time pressure group was more likely to deceive and induced a larger P3 amplitude than did the high-time pressure group. These results suggest that individuals with sufficient resources for self-control are more likely to resist temptation and less likely to engage in self-serving deception. Higher time pressure made subjects more likely to cheat. Deception is automatic and spontaneous under certain conditions. Ego depletion and high time pressure promote the occurrence of deception.

\section{INTRODUCTION}

People who are extremely exhausted, pressed, or busy are more likely to succumb to various temptations, even lying, than those who are energized and focused. Resisting unethical temptations requires selfcontrol (Gino et al., 2011; Tabatabaeian et al., 2015). Determining the automatic behavior of ego-depleted people when they have the opportunity to use unethical means to obtain greater benefits is challenging.

Two competing theories have been proposed: the "will" and the "grace" hypotheses (Greene \& Paxton, 2009). The will hypothesis posits that selfish and dishonest behaviors are usually instinctive, whereas the grace hypothesis proposes that honest behaviors are instinctive. Studies have yet to determine whether deception induced by ego depletion is spontaneous. This study indirectly evidences that deception induced by ego depletion may be spontaneous under high time pressure. No empirical study has been conducted on the influence of ego depletion on spontaneous deception under time pressure. Our study is based on the dual-process models in the field of moral conflict decision-making (Kahneman, 2011). These models include an intuitive System 1 that is fast and inflexible and a deliberate System 2 that is slow and flexible. We suggest that the deception induced by ego depletion may be spontaneous, and it is influenced by System 1, which enriches the exploration of instinct and moral decision-making.

Spontaneous deception refers to dishonest behavior that is automatic. According to social and cognitive psychology, spontaneous behavior is fast, parallel, and not easily disturbed. It is also characterized by automation (Evans, 2017; Shi \& Liu, 2019). Scholars hold diverse views on the reasons why self-control resource depletion increases deception. A meta-analysis suggested that egoism leads to an increase in lying behavior in people (Köbis et al., 2019). When people have an opportunity to deceive, rewards play a crucial role. The higher the reward, the easier it is for people to decide to engage in deception (Allingham \& Sandmo, 1972). When individuals are in a state of ego depletion, their self-control drops sharply, and they are more likely to exhibit selfish impulses. That is, such impulses increase the tendency of spontaneous decision-making (Anderman et al., 2009).

Corresponding author: Yiping Zhong, Cognition and Human Behavior Key Laboratory of Hunan Province, Hunan Normal University, Changsha, 410081, China.

Email:ypzhong@hunnu.edu.cn 
Ego depletion negatively affects execution resources, hampering the individual's ability to judge whether deception is moral or not (Gino et al., 2011). Therefore, the immoral behavior of ego-depleted individuals can be regarded as spontaneous. However, studies have revealed that deception is a complex cognitive process (Vrij et al., 2008; Vrij et al., 2011). Deception requires a considerable amount of time and energy (Suchotzki et al., 2017; Verschuere et al., 2018). When deception occurs, people must invest effort into clarifying the truth in their minds, and more cognitive skills are required in this complex cognitive process (Vrij et al., 2006). Therefore, immoral behaviors cannot be regarded as an automatic process in ego-depleted individuals. Studying the conditions of spontaneous deception is essential. In daily life, when people are confronted with the conflict between violating moral standards to meet their own interests and adhering to these moral standards, how they make decisions is a critical question. Research has revealed that cognitive control prompts cheaters to make honest decisions, and it enables honest people to exhibit deceptive tendencies (Speer et al., 2020). One possible reason for this phenomenon is that personal self-control ability can regulate people's behavior. Moreover, time pressure (Shalvi et al., 2012), sleep deprivation, and taxed self-regulation resources (Wagner et al., 2012) reduce people’s self-control ability, leading to an increase in immoral behavior in the presence of temptation. Therefore, exploring the conditions and brain mechanisms underlying spontaneous deception can enrich the dual processing model of self-serving deception.

Numerous studies have investigated the influence of self-control resources on deception, but an in-depth study on spontaneous deception is lacking. When people perform self-control tasks, they consume certain cognitive resources. In that moment, these resources are in a state of temporary exhaustion, which hampers an individual's performance in subsequent, even unrelated, self-control tasks. These resources are called self-control resources (Baumeister et al., 2007). The heavy consumption of self-control resources may result in their temporary depletion, which is referred to as ego depletion (Tice et al., 2007). In the process of self-control resource depletion, the automatic and instinctive cognitive process remains basically intact, but the restriction of conscious and complex thinking tends to result in cognitive errors (Pocheptsova et al., 2009). In one study, ego-depleted individuals exhibited poorer performance in logical reasoning tasks than those in a control group. However, no difference was noted in simple and automatic cognitive tasks, such as mechanical recitation and recall of general knowledge (Schmeichel et al., 2003). Whether ego depletion would trigger people's spontaneous deception reaction merits investigation. One study reported that individuals are more likely to use cognitive heuristic strategies in case of resource depletion (Pohl et al., 2013). Social heuristic strategies are a type of decision-making strategy that can save time and effort. Ego-depleted individuals tend to gradually shift to a social heuristic thinking mode when they consider ideal decisions (Masicampo \& Baumeister, 2008; Pocheptsova et al., 2009). Ego depletion causes individuals to pay greater attention to material rewards and increases their motivation for impulsive behavior. (Anderman et al., 2009). Therefore, ego-depleted individuals are unwilling to control themselves rather than unable to do so (Wu et al., 2019). This finding suggests that ego depletion causes an individual's motivation to shift from self-control to self-interest (Inzlicht \& Schmeichel, 2012). Some scholars have restricted participants' deliberate thinking through cognitive load (Welsh \& Ordonez, 2014), time pressure (Shalvi et al., 2012), mental or physical depletion (Kouchaki \& Smith, 2014), and priming of intuition concepts (Zhong, 2011) to increase self-serving dishonesty. These studies have revealed that deception is spontaneous under certain situations.

To examine whether deception is an automatic behavior under time pressure, researchers have employed various experimental operations but have obtained inconsistent results. Time pressure increases the likelihood of an individual's deceptive behavior. Under time pressure, regardless of whether the individual can justify their deceptive behavior, more deceptive behaviors occur (Shalvi et al., 2012). In situations involving temptation, the individual's instinctive response is self-interest, and even deception. Under time pressure, individuals instinctively employ deception to obtain rewards. A related study (Capraro, 2017) revealed contrasting finding that individuals are more honest under time pressure. On the basis of the social heuristic hypothesis, that study proposed that when individuals have no time to evaluate all the available options, they tend to rely on heuristic strategies to make the most appropriate choices in daily life. Honesty is the optimal approach in daily life, whereas deception is the most desirable option in the short term. Therefore, people are likely to be more honest under time pressure (Capraro, 2017). In these two studies, individuals provided spontaneous responses with diverse motivations. Therefore, exploring further which spontaneous response people select in different situations may yield insightful findings.

In this study, we indirectly explored the role of spontaneous thinking induced by time pressure and cognitive load in terms of moral judgment and behavior. Our results indicate that in the case of time pressure or cognitive load, participants tend to exhibit unethical behavior when making decisions. In cognitive and social psychology, when people make decisions under time pressure or cognitive load, they tend to favor spontaneity over deliberation (Tinghög et al., 2016). However, whether ego-depleted individuals still employ the instinctive approach to deceive in their effort to obtain more benefits remains to be seen. To address the aforementioned concerns, exploring the influence of time pressure and self-control resources on deception is imperative. Studies have investigated the effects of high time pressure and ego depletion on cooperative behavior. Their results revealed that time pressure can reduce cooperative behavior, and ego depletion can reduce cooperative behavior under certain conditions (Capraro \& Cococcioni, 2016). The effect of time pressure on automatic response is greater than that on reflective response, and time pressure can promote impulsive thinking (Rand et al., 2014). Ego depletion involves cognitive manipulation according to the self-regulatory strength model, which posits that all acts of self-control draw on a common resource. Ego-depleted individuals tend to act impulsively in subsequent tasks (Gino et al., 2011). When people are in situations of ego 
depletion or time pressure, they act on their instinctive, self-interested impulses.

Deception requires the participation of executive control. Imaging studies have revealed that deception involves the prefrontal cortex and its surrounding areas. When individuals deceive, the brain areas that are responsible for executive control are activated (Christ et al., 2008). Three executive functions increase cognitive cost in the process of deception: working memory, inhibition control, and task switching (Miyake et al., 2000). Working memory is involved when the truth is withheld, inhibition control is involved when the real response is suppressed, and task switching is involved when switching from an honest to deceptive response (Christ et al., 2008; Spence et al., 2001). The N2 and the P3 are electrophysiological markers of executive control, and they are regarded as markers of response inhibition or response conflict (Groom \& Cragg, 2015). Deception-related electroencephalography (EEG) studies have also indicated that both required deception and voluntary deception induced a larger N2 amplitude and a smaller P3 amplitude. Compared with an honest response, a deceptive response induced a larger N2 amplitude in the prefrontal area, and the increase in $\mathrm{N} 2$ amplitude reflected the improvement of the conflict monitoring level (Hu et al., 2015). Deception is generally regarded as a type of immoral behavior that violates social norms. Individuals experience conflict between cognition and morality when they deceive, which induces greater N2 amplitude (Ofen et al., 2016). Deception requires more executive control than does honesty. A study employing event-related potentials (ERPs) suggested that a reduced P3 amplitude reflects the involvement of executive control. When executive control demand increases, P3 amplitude decreases (Debey et al., 2012). When experimental tasks increase the need for executive control, P3 amplitude decreases. These tasks include perceptual load, dual tasks, fuzzy classification, and stimulus-response incompatibility (Christ et al., 2008; Cui et al., 2017; Hu et al., 2015; Wu et al., 2009). Moreover, ego depletion seriously impedes executive control (Debey et al., 2012). Therefore, we propose that $\mathrm{P} 3$ amplitude increases when individuals are in a state of ego depletion. In sum, deception is related to executive control. Self-control requires executive control, and ego depletion can weaken executive control. Thus, ego depletion is likely to result in more deceptive behaviors and induce an increase in P3 amplitude.

Some scholars have reported that individuals deceive more under time pressure (Shalvi et al., 2012). People tend to pursue rewards (Custers \& Aarts, 2010). In situations involving temptation, people automatically tend to be selfish, or even deceive (Shalvi et al., 2012). Studies have revealed that the P3 is a fast encoding of motivation (Carlson et al., 2015; Hajcak et al., 2010; Kleih et al., 2010; Lubman et al., 2008). The P3 is also a motivational signal of the midbrain limbic reward system (Cox et al., 2015; Flores et al., 2015). When an individual perceives the opportunity to obtain a reward, P3 amplitude increases (Pfabigan et al., 2014). Therefore, the P3 reflects the individual's instinctive motivation to pursue reward. Under time pressure, individuals automatically choose to deceive in order to obtain a greater monetary reward. We propose that time pressure also leads to larger P3 amplitude.

The purpose of this study was to explore the effects of time pressure and self-control resources on spontaneous deception. We used ERPs to examine whether deception induced by ego depletion is spontaneous or deliberate as well as its neural basis. Our research hypotheses were as follows: (a) individuals under high time pressure will be more likely to engage in deceptive behaviors and exhibit stronger deceptive tendencies than individuals not under time pressure; (b) compared with non-ego depleted individuals, ego-depleted individuals will exhibit a stronger deceptive tendency when a time pressure element is added. We used the Stroop task to manipulate the participants' selfcontrol resources. The visual perception task is the most widely used experimental paradigm in studies of deception behavior (Kouchaki \& Smith, 2014) because it can be used not only to determine deceptive tendency but also to identify deception. Kouchaki and Smith (2014) interpreted self-interest bias in this task as a condition where the participants indicate more dots on the right side in an ambiguous condition. By contrast, we interpret this as deceptive tendency. Before completing the visual perception task, the participants in the no-time pressure group were instructed to ensure accuracy, whereas those in the high-time pressure group were instructed to be fast and accurate.

\section{METHODS}

\section{Participants}

We randomly divided 80 participants into four groups, with 20 participants in each group. The EEG data of all participants were collected. Because of the heavy EEG artifacts of some participants, the data of 69 participants were finally analyzed. Participants were randomly assigned to four conditions: ego depletion with high time pressure $(n=$ $18)$, ego depletion without time pressure $(n=18)$, non-ego depletion with high time pressure $(n=16)$ and non-ego depletion without time pressure $(n=17)$. The participants were all right-handed and healthy, and they had no neurological diseases, no history of brain injury, normal vision or corrected visual acuity, and no color blindness. Before the experiment, the participants provided written informed consent, and they received a small reward after the experiment. The study was approved by the Ethics Committee of Hunan Normal University.

\section{Design}

We used a 2 (time pressure: high time pressure vs. no time pressure) $\times 2$ (self-control resources: depletion vs. nondepletion) betweensubjects design in the experiment. The dependent variables were the behavioral results (the number of deceptions and the extent of deceptive tendency) and the ERP results (N2 and P3 amplitudes).

\section{Procedure}

All the participants completed the experiment in a separate small room. The participants wore EEG caps to complete the Stroop task and visual perception task. The EEG data of the participants were collected during the visual perception task but not during the Stroop 
task. The instructions and experimental programs were presented on a computer. First, participants in the depletion group completed a 15 min color discrimination Stroop task (Neshat-Doost et al., 2008). In the Stroop task, the participants were instructed to identify the font color of the word, but not the word being spelled out. The participants were required to identify the red "red," the red "blue," the blue "blue," and the blue "red." The presentation time of the stimulation was 500 ms, including 25 trials for each of the four conditions, yielding 100 trials. The participants in the nondepletion group were only required to complete a simple task of font color discrimination in the same time (see Figure 1). In this task, the presentation time of the stimulus was $500 \mathrm{~ms}$, and 100 trials were conducted. Subsequently, the operation test was performed to assess the self-control resources of different groups. A 7-point scale, ranging from 1 (very easy) to 7 (very difficult), was used to evaluate task difficulty. The degree of effort required for the task was also evaluated from 1 (no effort required) to 7 (great effort required). After the assessment, the participants performed a visual perception task.

The visual perception task was used to examine the participants' deceptive behavior (Kouchaki \& Smith, 2014). In this task, 200 squares with red dots were presented to the participants. The square was divided into left and right halves by a diagonal line, and 40 red dots were randomly and unevenly distributed on both sides of the line. In total, 80 trials had significantly more red dots on the left, 20 trials had significantly more red dots on the right, and 100 trials had a nearly equal number of red dots on both sides. In the experiment, the participants were instructed to determine which side of each square had more red dots; the participants were informed that they would receive $¥ 0.5$ for each time they judged that more red dots were located on the right. When they judged that more red dots were located on the left, they received $¥ 0.1$. The researcher ensured that the participants understood the reward rules. Finally, the reward was calculated according to the number of judgments instead of the number of correct judgments. In the case of obvious distribution, when there were more red dots on the left side of the line, the participants judging that there were more red dots on the right was considered as deception. In the case of unclear point distribution, 20 red dots were randomly distributed on both the left and right sides, making it impossible for the participants to accurately determine which side had more red dots

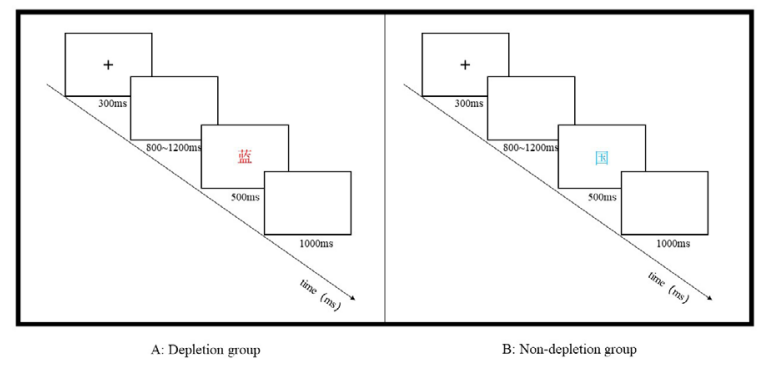

FIGURE 1.

Stroop task.

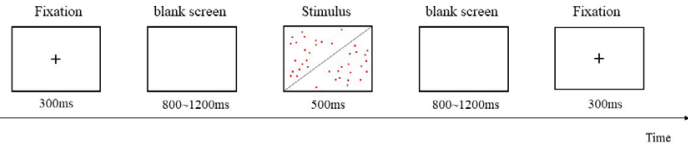

FIGURE 2.

A trial in a visual perception task.

within $500 \mathrm{~ms}$. If the participants determined that the right side had more red dots, deceptive tendency was coded.

In the experimental procedure, a cross was presented in the center of the screen for $300 \mathrm{~ms}$. Subsequently, a random black screen was presented for 800-1200 ms. Then, a target stimulus was presented for $300 \mathrm{~ms}$. Finally, a black screen was displayed for $1000 \mathrm{~ms}$ (see Figure 2). This experiment involved three conditions: more red dots on the left, more red dots on the right, and an approximately equal number of red dots on the left and right sides. Participants in the high-timepressure group were instructed to press the selection button quickly and accurately when the target stimulus was presented, whereas participants in the no-time pressure group were instructed to simply answer accurately. Participants pressed " 1 " if they thought more red dots were located on the left, and they pressed " 2 " if they thought more red dots were located on the right. After the practice phase, the participants completed 200 trials of the formal experiment. The 200 trials were completed twice. Finally, all participants completed the time stress measurement questionnaire $(\alpha=0.85)$. A 7-point Likert scale was used, ranging from 1 (complete disagreement) to 7 (complete agreement; Inman \& McAlister, 1994).

\section{EEG Records}

The Neuro ERP system was used for analysis. The EEG was recorded using a 64-conductive cap expanded by the international 10-20 system. The left mastoid line was used as the reference electrode for online recording, and the same line was converted to bilateral mastoid as the reference electrode after offline recording. The horizontal ophthalmic was recorded by placing electrodes on the lateral side of both eyes offline, and the vertical ophthalmic (VEOG) was recorded by placing electrodes above and below the left eye. The filter band pass was $0.05-70 \mathrm{~Hz}$, the sampling frequency was $1000 \mathrm{~Hz} /$ conduction, and the scalp impedance was $<5 \mathrm{~K} \Omega$.

\section{ERP Data Processing}

After continuous EEG recording was conducted, the data were processed offline. NeuroScan was used to correct the VEOG and sufficiently discharged other artifacts. The EEG data after stimulation presentation were analyzed and superimposed with baseline EEG. An amplitude greater than $\pm 100 \mu \mathrm{V}$ was regarded as an artifact and automatically eliminated. The data regarding deceptive tendency and deception frequency of the participants in the visual perception task were analyzed, and the deception frequency and deceptive tendency were analyzed as a new dimension of deception. The analysis time period was from $200 \mathrm{~ms}$ before stimulus presentation (baseline) to 1000 ms after stimulus presentation. On the basis of the butterfly diagram 
analyzed offline and related research results, the average amplitudes of N2 (250-400 ms) and P3 (600-800 ms) were statistically analyzed (Carlson et al., 2015; Cui et al., 2017). The six N2 electrodes selected in the frontal area were F4, FZ, F3, FC3, FCz, and FC4. The six electrodes selected in the top area of $\mathrm{P} 3$ were $\mathrm{CP} 3, \mathrm{CPz}, \mathrm{CP} 4, \mathrm{P} 3, \mathrm{Pz}$, and P4. Accordingly, the average amplitude of the ERP components was analyzed using three-factor repeated-measures analysis of variance (ANOVA). Each factor was set as 2 (self-control resources: depletion vs. nondepletion) $\times 2$ (time pressure: high time pressure vs. no time pressure $) \times 6$ [electrode location: frontal area (F4, Fz, F3, FC3, FCz, and $\mathrm{FC} 4$ ), top area (CP3, CPz, CP4 $\mathrm{P} 3, \mathrm{Pz}$, and P4)]. The degrees of freedom of the $\mathrm{F}$ ratios were corrected using the Greenhouse-Geisser method.

\section{RESULTS}

\section{Manipulation Check}

In the Stroop task operation test, the accuracy rate of the depletion group $(M=91.17, S D=21.22)$ and nondepletion group $(M=92.18$, $S D=15.71)$ reached $90 \%$, indicating that participants had the ability to complete these two tasks. The results of an independent-samples $\mathrm{t}$ test revealed that the depletion group had a significantly longer response time than the nondepletion group, $t(67)=-9.23, p<.001$.

As for the subjective evaluation of task difficulty, compared with the participants in the nondepletion group, those in the depletion group rated the task as significantly more difficult, $t(67)=3.78, p<$ .05. Regarding the subjective evaluation of effort, the independentsamples $\mathrm{t}$ test indicated no significant difference between the two groups, $t(67)=1.21, p>.05$.

In terms of time pressure evaluation, the participants in the timepressure group $(M=5.21, S D=0.81)$ experienced significantly more time stress than those in the no-time pressure group, $M=2.91, S D=$ $0.82 ; t(67)=-7.37, p<.01$.

\section{Behavior Results}

\section{DECEPTION AND DECEPTIVE TENDENCY}

A two-factor ANOVA for deceptive behavior indicated that the main effect of time pressure was significant, $F(1,65)=10.65, p<$ $.01, \eta_{\mathrm{p}}^{2}=0.16$, and the high-time pressure group $(M=10.46, S D=$ 11.03) exhibited more instances of deception than did the no-time pressure group $(M=2.23, S D=7.33)$. The main effect of self-control resources was nonsignificant, $F(1,65)=0.06, p=.8$, and we observed no significant difference between the depletion group $(M=7.43, S D=$ $12.17)$ and nondepletion group $(M=6.21, S D=8.26)$. The interaction between time pressure and self-control resources was nonsignificant, $F(1,65)=2.58, p=.11$. Under high time pressure, the depletion group $(M=12.71, S D=14.09)$ exhibited more instances of deception than did the nondepletion group $(M=8.06, S D=6.01)$. By contrast, the depletion group $(M=0.54, S D=1.45)$ had fewer deceptions than did the nondepletion group $(M=3.92, S D=10.19)$ in the absence of time pressure. Regarding the instances of deceptive tendency, the main effect of time pressure was significant. The no-time pressure group ( $M$ $=81.77, S D=16.26)$ exhibited more deceptive tendency than did the high-time pressure group $(M=66.36, S D=17.76), F(1,65)=12.06$, $p<.001, \eta_{\mathrm{p}}^{2}=0.18$. The main effect of self-control resources was nonsignificant. We observed no significant differences between the depletion group $(M=73.6, S D=17.22)$ and nondepletion group $(M$ $=72.69, S D=20.31), F(1,65)=0.01, p=.95$. The interaction between time pressure and self-control resources was nonsignificant, $F(1,65)$ $=2.51, p=.12$. Under high time pressure, the depletion group $(M=$ 69.94, $S D=14.54$ ) exhibited more instances of deception than did the nondepletion group $(M=62.56, S D=20.43)$. By contrast, the depletion group $(M=78.38, S D=19.77)$ exhibited fewer deceptions than did the nondepletion group $(M=85.15, S D=11.63)$ in the absence of time pressure (see Figure 3).

\section{REACTION TIME OF DECEPTION AND DECEPTIVE TENDENCY}

A two-factor ANOVA revealed that the main effect of time pressure was significant for the response time of deception, $F(1,65)=$ $62.81, p<.001, \eta_{\mathrm{p}}^{2}=0.53$, and the reaction time of the high-timepressure group $(M=340.53, S D=42.44)$ was longer than that of the no-time-pressure group $(M=75.35, S D=183.05)$. The main effect of self-control resources was nonsignificant, $F(1,65)=0.08, p=.78$, and we observed no significant difference in response time between the depletion group $(M=230.29, S D=189.02)$ and nondepletion group $(M=216.83, S D=177.2)$. The interaction between time pressure and self-control resources was nonsignificant, $F(1,65)=0.001, p=.94$. As for the reaction time of deceptive tendency, the main effect of time pressure was significant, $F(1,65)=73.48, p<.001, \eta_{\mathrm{p}}^{2}=0.57$, and the reaction time of the no-time pressure group $(M=924.25, S D=346.47)$ was longer than that of the high-time pressure group $(M=397.67, S D$ $=32.66)$. The main effect of self-control resources was nonsignificant, $F(1,65)=0.2, p=.66$, and we observed no significant difference in response time between the depletion group $(M=637.81, S D=359.86)$ and nondepletion group $(M=621.35, S D=343.73)$. The interaction between time pressure and self-control resources was nonsignificant, $F(1,65)=0.16, p=.69$ (see Figure 4$)$.

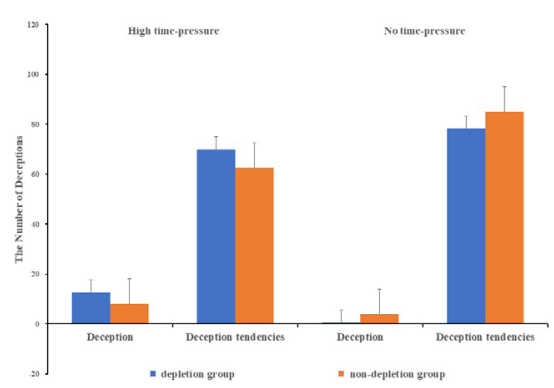

FIGURE 3.

Deception and deception tendency in each group. 


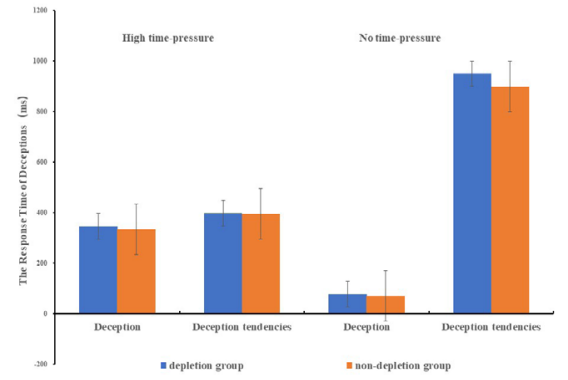

FIGURE 4.

Reaction time of deception and deception tendency in each group.

\section{RESULTS OF THE NEW DIMENSION OF DECEPTION}

The frequencies of deception and deceptive tendency were transformed into ratios, forming a new dimension of deception. We performed a three-factor repeated-measures ANOVA of 2 (self-control resources: depletion vs. nondepletion) $\times 2$ (time pressure: high time pressure vs. no time pressure) $\times 2$ (deception: deceptive behavior, deceptive tendency). The main effect of deception was significant, $F(1,65)$ $=868.98, p<.01, \eta_{\mathrm{p}}^{2}=0.94$, and the instances of deceptive tendency $(M=0.73, S D=0.19)$ were significantly higher than those of deceptive behavior $(M=0.07, S D=0.1)$. The interaction between deception and time pressure was significant, $F(1,65)=26.56, p<.01, \eta_{\mathrm{p}}^{2}=0.33$. Simple effect analysis revealed that the high-time pressure group exhibited more deceptive behavior than the no-time pressure group, and the deceptive tendency of the no-time pressure group was greater than that of the high-time pressure group $(p=.001)$. The interaction among other variables was nonsignificant.

\section{ERP RESULTS FOR N2 (250-400 MS)}

A repeated-measures ANOVA revealed that the main effect of self-control resources was nonsignificant, $F(1,65)=0.01, p=.91$. We observed no significant difference in amplitude between the depletion group $(-2.17 \pm 3.87)$ and nondepletion group $(-2.47 \pm 4.68)$. The main effect of time pressure was nonsignificant, $F(1,65)=0.78, p=$ .38. We noted no significant difference in amplitude between the time pressure group $(-2.73 \pm 4.68)$ and no-time pressure group (-1.77 \pm 3.61). The interaction between self-control resources and time pressure was nonsignificant, $F(1,65)=1.13, p=.29$ (see Figure 5, left panel). A significant main effect was observed for electrode location, $F(1,65)=15.76, p<.001, \eta_{\mathrm{p}}^{2}=0.23$. The amplitude of Fz $(-3.09 \pm$ $0.64)$ was the largest, and the amplitudes of F3 $(-3.01 \pm 0.67)$ and Fz $(-3.09 \pm 0.64)$ were significantly larger than those of F4 $(-1.55 \pm 0.58)$ and FC4 $(-1.12 \pm 0.55)$. The amplitude difference between FC3 $(-2.28$ $\pm 0.58)$ and $\mathrm{FCz}(-2.44 \pm 0.69)$ was nonsignificant. The interaction between electrode position and time pressure was significant, $F(1,65)$ $=6.07, p<.001, \eta_{\mathrm{p}}^{2}=0.10$. The simple effect analysis revealed that the F3 amplitude of the time pressure group was significantly higher than that of the no-time pressure group $(p=.03)$. None of the other interactions were significant (see Figure 6).

Deceiving behavior and deceptive tendency were taken as a new dimension of deception. A repeated-measures ANOVA revealed no significant main effect for deception, $F(1,65)=1.25, p=.27$. The main effect of time pressure was significant, $F(1,65)=16.90, p<.001, \eta_{p}^{2}$ $=0.24$. The amplitude of the time-pressure group $(15.24 \pm 1.89)$ was significantly higher than that of the no-time-pressure group (3.38 \pm 2.18). The main effect of self-control resources was nonsignificant, $F(1,65)=0.12, p=.73$. The main effect of electrode location was nonsignificant, $F(5,325)=2.36, p=.11$. None of the other interactions were significant (see Figure 7, left panel).

\section{ERP RESULTS FOR P3 (600-800 MS)}

A repeated-measures ANOVA revealed that the main effect edge of self-control resources was significant, $F(1,65)=3.43, p=.069, \eta_{\mathrm{p}}^{2}$ $=0.069$. The depletion group $(3.72 \pm 5.19)$ exhibited a larger P3 amplitude than the nondepletion group $(1.09 \pm 5.76)$. The main effect of time pressure was significant, $F(1,65)=6.93, p=.01, \eta_{\mathrm{p}}^{2}=0.11$. The high-time pressure group $(4.03 \pm 6.18)$ induced greater $\mathrm{P} 3 \mathrm{am}$ plitude than the no-time pressure group $(0.36 \pm 3.90)$. The interaction between time pressure and self-control resources was nonsignificant, $F(1,65)=0.17, p=.69$; see figure 5 , right panel). A significant main effect was observed for electrode location, $F(1,65)=13.76, p<.001$, $\eta_{\mathrm{p}}^{2}=0.20$. The amplitude of $\mathrm{CPz}(4.27 \pm 0.91)$ was the largest, and the amplitudes of $\mathrm{CPz}(4.27 \pm 0.91)$ and $\mathrm{CP} 4(3.78 \pm 0.88)$ were significantly higher than those of $\mathrm{P} 3(0.33 \pm 0.72), \mathrm{Pz}(0.69 \pm 0.78)$, and $\mathrm{P} 4$ $(0.69 \pm 0.78)$. The interaction of electrode location and time pressure was significant, $F(1,65)=5.65, p<.001, \eta_{\mathrm{p}}^{2}=0.10$. The simple effect analysis indicated that the amplitudes of $\mathrm{CPz}, \mathrm{CP} 4$, and $\mathrm{P} 4$ were significantly larger in the high-time pressure group than in the no-time pressure group $(p<.05)$. None of the other interactions were significant (see Figure 6).

Deceptive behavior and deceptive tendency were employed as a new dimension of deception. A repeated-measures ANOVA revealed that the main effect of time pressure was nonsignificant, $F(1,65)=$ $2.83, p=.10$. The main effect edge of self-control resources was significant, $F(1,65)=3.41, p=.07, \eta_{\mathrm{p}}^{2}=0.06$. The depletion group ( 4.18 \pm 1.33 ) exhibited a larger $\mathrm{P} 3$ amplitude than the nondepletion group $(0.65 \pm 1.38)$. The main effect of deception was nonsignificant, $F(1,65)$ $=0.10, p=.76$. The main effect of electrode location was significant, $F(5,325)=5.91, p=.008, \eta_{\mathrm{p}}^{2}=0.10$. The amplitudes of $\mathrm{CPz}(4.90 \pm$ $0.77)$ and $\mathrm{CP} 4(3.99 \pm 0.96)$ were significantly greater than those of $\mathrm{P} 3$ $(-0.38 \pm 1.90)$ and P4 (2.16 \pm 0.84$)$, and the amplitude of CP3 (1.75 \pm 1.47) was significantly larger than that of $\mathrm{P} 3(0.38 \pm 1.90)$. Moreover, the amplitude of $\mathrm{CPz}(4.90 \pm 0.77)$ was significantly larger than that of $\mathrm{Pz}(2.06 \pm 0.61)$. The interaction between electrode location and time pressure was significant, $F(1,65)=3.54, p=.046, \eta_{\mathrm{p}}^{2}=0.06$. The simple effect analysis revealed that the amplitudes of $\mathrm{CPz}, \mathrm{CP} 4, \mathrm{Pz}$, and $\mathrm{P} 4$ in the high-time-pressure group were significantly larger than those of the no-time-pressure group $(p<.05)$. None of the other interactions were significant (see Figure 7, right panel). 


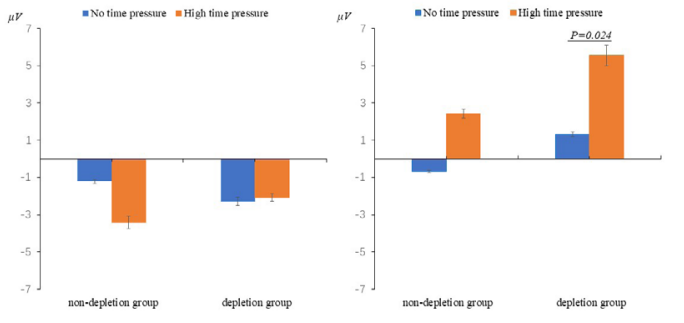

FIGURE 5.

The bar diagram of the mean amplitude of all analysis points. Left: N2. Right: P3.

\section{DISCUSSION}

Self-interested deception is instinctive, and it is influenced by cognitive, motivational, and situational factors (Köbis et al., 2019). By introducing the time pressure variable, this study indirectly evidenced that deceptive behavior caused by ego depletion may be spontaneous, which lays the foundation for future research. The principal findings of this study are discussed in the following sections.

\section{More Spontaneous Self-Serving Deceptive Behaviors Occur Under High Time Pressure, and More Deceptive Tendencies Occur Under No Time Pressure}

The behavioral results revealed that the time pressure group exhibited more deceptive behaviors, which is consistent with previous studies. Individuals are more inclined to deceive under high time pressure, and they intuitively opt for self-serving deception under time pressure (Shalvi et al., 2012). Under the condition of anonymity, the individual's automatic response is self-interested, even to the point of employing deception. Notably, the no-time pressure group exhibited more deceptive tendency than did the high time-pressure group. When previous researchers used the visual perception task to study deception, they defined participants' selections for maximizing monetary rewards in unclear point distribution contexts as self-serving bias (Kouchaki \& Smith, 2014). Our research defined this behavior as deceptive tendency (Fan et al., 2016). The results for reaction time revealed a significant difference in deceptive tendency between the high-time
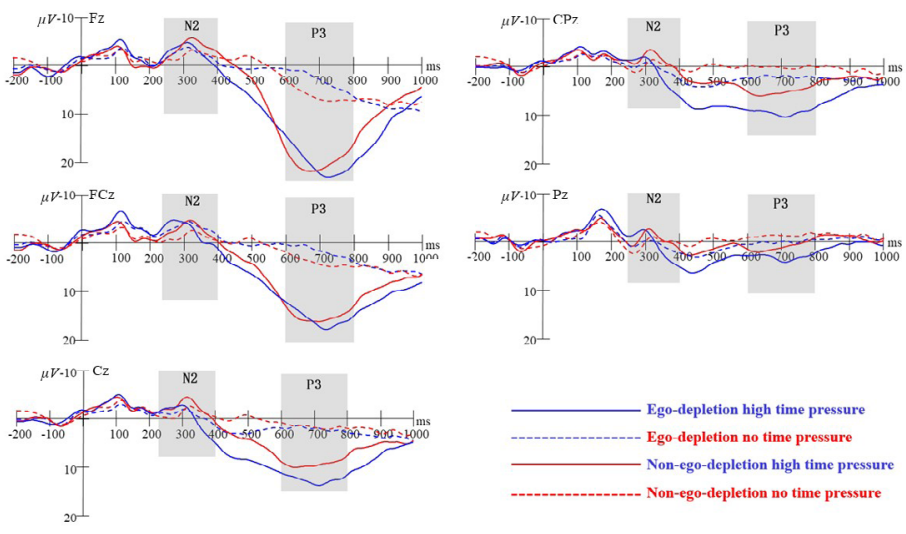

FIGURE 6.

The total average of ERPs induced on Fz, FCz, Cz, CPz, and Pz when the participants were inclined to deceive.

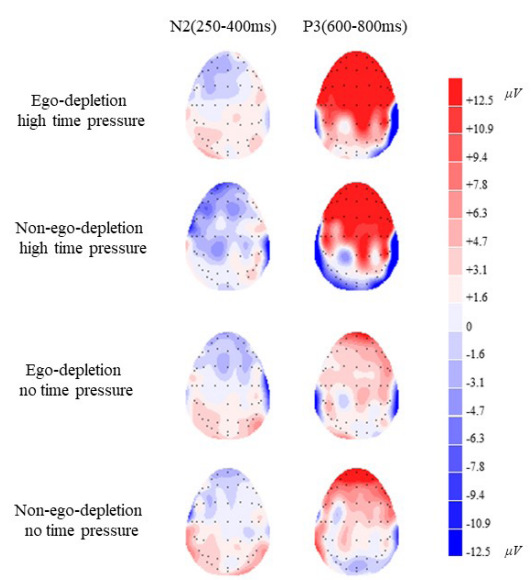

FIGURE 7.

A topographic map of the brain of a participant with the tendency to deceive. 
pressure group and the no-time pressure group, with the no-time pressure group exhibiting a longer reaction time. A study by Pittarello et al. (2015) indicated that the unclear points distribution situation increases people's self-interested behavior, and the lack of clarity can provide a justification for moral disengagement. In the absence of time pressure, individuals had sufficient time to rationalize their motivation and tended to deceive more, which is consistent with the findings of previous studies (Shalvi, 2012). Time pressure increased individuals' deceptive behaviors. Under high time pressure, individuals deceived more regardless of whether they could justify their deceptive behaviors. In situations involving temptation, people's automatic response is self-interested behavior, or even deception, to maximize the potential benefit. Under time pressure, an individual intuitively opts to deceive for the reward.

The EEG results revealed that the amplitude of N2 in the high-time pressure group was significantly larger than that in the no-time pressure group, which is consistent with the behavioral results. The N2 is an electrophysiological marker of executive control, and it responds to inhibition or conflict (Groom \& Cragg, 2015). Studies have indicated that deception elicits a larger N2 amplitude in the prefrontal region than does an honest response; N2 indicates that the conflict monitoring level is increasing (Hu et al., 2015). Deception is generally regarded as an immoral behavior that violates social norms. When participants deceive, they face the dual conflict of cognition and morality (Ofen et al., 2016), which results in a greater N2 amplitude. In terms of the P3 component, that of the time pressure group was larger than that of the no-time pressure group. As a rapid encoder of motivation (Carlson et al., 2015; Hajcak et al., 2010; Kleih et al., 2010; Lubman et al., 2008) and a motivational signal of the midbrain limbic reward system (Cox et al., 2015; Flores et al., 2015), the P3 reflects the individual's intuitive motivation to pursue reward, and a large $\mathrm{P} 3$ amplitude is the neural signal of intuitive prosocial motivation (Carlson et al., 2015). When a situation involves monetary temptation, the individual's spontaneous response is self-interested, even if they need to deceive to benefit. Under time pressure, the individual intuitively opts to deceive to maximize the reward. The P3 amplitude in the high-time pressure group was larger than that of the no-time pressure group, which is also reflected in the executive control. The cognitive load induced by time pressure increases the demands on executive control and makes deceiving more difficult. Shalvi et al. (2012) reported that individuals are more likely to deceive under high time pressure. However, how time pressure affects deception remains unclear. Ego depletion can weaken executive control (Debey et al., 2012). In the current study, the time-pressure group exhibited a larger P3 amplitude, which indicates that cognitive load caused by time pressure may also affect the executive control process, weaken the ability to resist temptation, and generate more deceptive behaviors.

\section{Ego Depletion and High Time Pressure Promote The Occurrence of Self-Serving Deception}

The behavioral results indicated an opposite pattern between the depletion and nondepletion groups under different time pressures in terms of deception and deceptive tendency. According to previous studies, ego-depleted individuals exhibit more deceptions and deceptive tendencies than those who were not ego-depleted; this result may be attributed to the long experimental time. That is, the depleted selfcontrol resources might have partially recovered.

The EEG results in the current study revealed that the depletion group exhibited a larger P3 amplitude than the nondepletion group, which is consistent with the finding of a previous study. Wu et al. (2019) reported that ego depletion caused individuals to pay more attention to monetary rewards and increased the motivation of impulsive behavior. Ego depletion also resulted in individuals' motivation changing from self-control to self-interest (Inzlicht \& Schmeichel, 2012). These results may indicate that in the case of self-interest, deception is a type of intuitive reaction that can be induced by manipulating time pressure and self-control resources. Furthermore, the P3 reflects the participation of executive control. Studies have shown that deception requires more executive control than does honesty. Eventrelated potential research has indicated that when the demand for executive control increases and more cognitive resources are used, P3 amplitude decreases (Christ et al., 2008; Cui et al., 2017). Ego depletion can weaken executive control (Debey et al., 2012). These results may also indicate that deception is related to executive control, that self-control requires executive control, and that ego depletion can weaken executive control. Therefore, relative to typical conditions, ego depletion results in more deceptive behaviors and induces a larger P3 amplitude.

\section{Similarities and Differences of The Effects of Ego Depletion and Cognitive Load on Cognition and Behavior}

Some studies have elucidated the role of intuitive thinking induced by time pressure and cognitive load in moral judgment and behavior (Tinghög et al., 2016). The similarities and differences between the effects of ego depletion and cognitive load on cognition and behavior have been a popular research topic in recent years (Maranges et al., 2017; Van Dillen et al., 2013). Cognitive load mitigates the awareness of aversion or negative emotion information, which minimizes negative emotional experience and reduces the impact of negative emotions on cognition. However, ego depletion does not play the same role (Maranges et al., 2017). Activity in the left amygdala increased in ego-depleted individuals when they faced negative scenes (Wagner \& Heatherton, 2012). However, cognitive load reduced the neural responses to positive and negative pictures (Pessoa et al., 2002). Furthermore, high cognitive load reduces the activation of the amygdala and the ventral striatum (Erk et al., 2007). These results indicate that ego depletion and cognitive load have different effects. Ego depletion enhances emotional processing, whereas cognitive load inhibits emotional processing (Van Dillen et al., 2013). Emotion is both the cause and effect of deception. Emotion not only provides motivation for deception but also influences the decision-making, construction, and expression of deception (Walczyk et al., 2014). Whether the ef- 
fects of ego depletion and cognitive load on deception differ remains unknown. Time pressure can activate emotional components and indirectly affect cognitive load. The conflict between the time pressure caused by the limited completion time and the actual time spent leads to a high degree of emotional reaction (Galy et al., 2012). Our study revealed that cognitive load caused by ego depletion and time pressure induced a larger P3 amplitude. These results suggest that both ego depletion and time pressure affect the executive control process of deception.

\section{LIMITATIONS}

We used a visual perception task to study deceptive behavior, and we observed that participants exhibited greater deceptive tendency and less deceptive behavior, which may be attributed to the long experimental time. In the second half of the experiment, the depletion of self-control resources may have partially recovered. In future studies, researchers can improve the experimental design, increase the sample size, and improve the pretest and posttest of the experiments to avoid these problems. Moreover, in terms of technical means, time-frequency analysis can be used to explore the neural mechanism of the deceptive intuitive self-interested motivation of deception. Researchers can also use the single trial analysis technique to analyze how the latency variation between each trial affects the intuitive self-serving motivation of deception.

\section{ACKNOWLEDGEMENTS}

This work was supported in part by grants from the Hunan Province Philosophy Social Science Project (18YBQ095). The funder had no role in study design, data collection and analysis, decision to publish, or preparation of the manuscript.

\section{REFERENCES}

Allingham, M. G., \& Sandmo, A. (1972). Income tax evasion: A theoretical analysis. In S. James (Ed.), Taxation: Critical Perspectives on the World Economy (Vol. 3, pp. 323-338). Routledge

Anderman, E. M., Cupp, P. K., \& Lane, D. (2009). Impulsivity and academic cheating. The Journal of Experimental Education, 78(1), 135-150.doi: 10.1080/00220970903224636 السلسلة

Baumeister, R. F., Vohs, K. D., \& Tice, D. M. (2007). The strength model of self-control. Current Directions in Psychological Science,

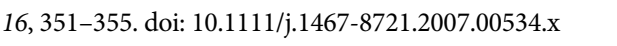

Capraro, V. , \& Cococcioni, G. (2016). Rethinking spontaneous giving: extreme time pressure and ego-depletion favor self-regarding reactions. Scientific Reports, 6, 27219. doi: 10.1038/srep27219 السلس

Capraro, V. (2017). Does the truth come naturally? Time pressure increases honesty in one-shot deception games. Economics Letters, 158, 54-57. doi: 10.1016/j.econlet.2017.06.015 الملسلسلة

Carlson, R. W., Aknin, L. B., \& Liotti, M. (2015). When is giving an impulse? An ERP investigation of intuitive prosocial behavior. Social Cognitive and Affective Neuroscience, 11, 1121-1129. doi: 10.1093/ scan/nsv077 س山س

Christ, S. E., Van Essen, D. C., Watson, J. M., Brubaker, L. E., \& McDermott, K. B. (2008). The contributions of prefrontal cortex and executive control to deception: Evidence from activation likelihood estimate meta-analyses. Cerebral Cortex, 19, 1557-1566. doi: 10.1093/cercor/bhn189 الم

Cox, A., Kohls, G., Naples, A. J., Mukerji, C. E., Coffman, M. C., Rutherford, H. J., . . \& \& McPartland, J. C. (2015). Diminished social reward anticipation in the broad autism phenotype as revealed by event-related brain potentials. Social Cognitive and Affective Neuroscience, 10, 1357-1364. doi: 10.1093/scan/nsv024 السلسلسلسا

Cui, F., Wu, S., Wu, H., Wang, C., Jiao, C., \& Luo, Y. (2017). Altruistic and self-serving goals modulate behavioral and neural responses in deception. Social Cognitive and Affective Neuroscience, 13, 63-71. doi: $10.1093 /$ scan/nsx138 سلس

Custers, R., \& Aarts, H. (2010). The unconscious will: How the pursuit of goals operates outside of conscious awareness. Science, 329(5987), 47-50. doi: 10.1126/science.1188595 المالسلسلس

Debey, E., Verschuere, B., \& Crombez, G. (2012). Lying and executive control: An experimental investigation using ego depletion and goal neglect. Acta Psychologica, 140, 133-141. doi: 10.1016/j.actpsy.2012.03.004 السلس

Erk, S., Kleczar, A., \& Walter, H. (2007). Valence-specific regulation effects in a working memory task with emotional context. Neuroimage, 37, 623-632. doi: 10.1016/j.neuroimage.2007.05.006 لمالسلسلس

Evans, J. S. B. (2017). Dual-process theories. In L. J. Ball, \& V. A. Thompson (Eds.). International handbook of thinking and reasoning (pp. 173-188). Routledge.

Fan, W., Zhong, Y., LI, H., Meng, C., You, C., \& Fu, X. (2016). The influence of self-control in the perceived of deception and deception. Acta Psychologica Sinica, 48, 845-856. doi: 10.3724/SP.J.1041.2016.00845 السلسلسل Flores, A., Münte, T. F., \& Doñamayor, N. (2015). Event-related EEG responses to anticipation and delivery of monetary and social reward. Biological Psychology, 109, 10-19. doi: 10.1016/j.biopsy-

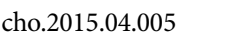

Galy, E., Cariou, M., \& Mélan, C. (2012). What is the relationship between mental workload factors and cognitive load types? International Journal of Psychophysiology, 83, 269-275. doi: 10.1016/j.ijpsycho.2011.09.023 السلسلس

Gino, F., Schweitzer, M. E., Mead, N. L., \& Ariely, D. (2011). Unable to resist temptation: How self-control depletion promotes unethical behavior. Organizational Behavior and Human Decision Processes, 115, 191-203. doi: 10.1016/j.obhdp.2011.03.001 المسلس

Groom, M. J. , \& Cragg, L. (2015). Differential modulation of the N2 and P3 event-related potentials by response conflict and inhibition. Brain \& Cognition, 97, 1-9. doi: 10.1016/j.bandc.2015.04.004 سلس

Greene, J. D. , \& Paxton, J. M. . (2009). Patterns of neural activity associated with honest and dishonest moral decisions. Proceedings of the National Academy of ences of the United States of America, 106. doi: 10.1073/pnas.0900152106 الم السلسلس

Hajcak, G., MacNamara, A., \& Olvet, D. M. (2010). Event-related potentials, emotion, and emotion regulation: An integra- 
tive review. Developmental Neuropsychology, 35, 129-155. doi: 10.1080/87565640903526504 سلس

Hu, X., Pornpattananangkul, N., \& Nusslock, R. (2015). Executive control-and reward-related neural processes associated with the opportunity to engage in voluntary dishonest moral decision making. Cognitive, Affective, \& Behavioral Neuroscience, 15, 475-491. doi: 10.3758/s13415-015-0336-9 سلس

Inman, J. J., \& McAlister, L. (1994). Do coupon expiration dates affect consumer behavior? Journal of Marketing Research, 31, 423-428. doi: $10.2307 / 3152229$ |لس

Inzlicht, M., \& Schmeichel, B. J. (2012). What is ego depletion? Toward a mechanistic revision of the resource model of selfcontrol. Perspectives on Psychological Science, 7, 450-463. doi: 10.1177/1745691612454134 السليلس

Kahneman, D. (2011). Thinking, fast and slow. Macmillan.

Kleih, S. C., Nijboer, F., Halder, S., \& Kübler, A. (2010). Motivation modulates the P300 amplitude during brain-computer interface use. Clinical Neurophysiology, 121, 1023-1031. doi: 10.1016/j. clinph.2010.01.034 سلس

Köbis, N. C., Verschuere, B., Bereby-Meyer, Y., Rand, D., \& Shalvi, S. (2019). Intuitive honesty versus dishonesty: Meta-analytic evidence. Perspectives on Psychological Science, 14, 778-796. doi: 10.1177/1745691619851778 البلسلس

Kouchaki, M., \& Smith, I. H. (2014). The morning morality effect: The influence of time of day on unethical behavior. Psychological Science, 25, 95-102. doi: 10.1177/0956797613498099 الفيلس

Lubman, D. I., Allen, N. B., Peters, L. A., \& Deakin, J. F. W. (2008). Electrophysiological evidence that drug cues have greater salience than other affective stimuli in opiate addiction. Journal of Psychopharmacology,

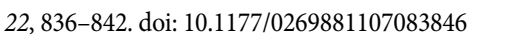

Maranges, H. M., Schmeichel, B. J., \& Baumeister, R. F. (2017). Comparing cognitive load and self-regulatory depletion: Effects on emotions and cognitions. Learning and Instruction, 51, 74-84. doi: 10.1016/j.learninstruc.2016.10.010 السلسلس

Masicampo, E. J., \& Baumeister, R. F. (2008). Toward a physiology of dual-process reasoning and judgment: Lemonade, willpower, and expensive rule-based analysis. Psychological Science, 19, 255-260. doi: 10.2307/40064920 سلس

Miyake, A., Friedman, N. P., Emerson, M. J., Witzki, A. H., Howerter, A., \& Wager, T. D. (2000). The unity and diversity of executive functions and their contributions to complex "frontal lobe" tasks: A latent variable analysis. Cognitive Psychology, 41, 49-100. doi: 10.1006/cogp.1999.0734 المسلسلس

Neshat-Doost, H. T., Dalgleish, T., \& Golden, A. M. J. (2008). Reduced specificity of emotional autobiographical memories following selfregulation depletion. Emotion, 8, 731-736. doi: 10.1037/a0013507 المالسلس

Ofen, N., Whitfield-Gabrieli, S., Chai, X. J., Schwarzlose, R. F., \& Gabrieli, J. D. (2016). Neural correlates of deception: Lying about past events and personal beliefs. Social Cognitive and Affective Neuroscience, 12, 116-127. doi: 10.1093/scan/nsw151 المبلسلسلة

Pessoa, L., McKenna, M., Gutierrez, E., \& Ungerleider, L. G. (2002). Neural processing of emotional faces requires attention. Proceedings of the National Academy of Sciences, 99, 11458-11463. doi: 10.1073/ pnas.172403899 سلس

Pfabigan, D. M., Seidel, E. M., Sladky, R., Hahn, A., Paul, K., Grahl, A., ... \& Windischberger, C. (2014). P300 amplitude variation is related to ventral striatum BOLD response during gain and loss anticipation: An EEG and fMRI experiment. NeuroImage, 96, 12-21. doi: 10.1016/j.neuroimage.2014.03.077 الس

Pocheptsova, A., Amir, O., Dhar, R., \& Baumeister, R. F. (2009). Deciding without resources: Resource depletion and choice in context. Journal of Marketing Research, 46, 344-355. doi: 10.2139/ ssrn.955427 الم

Pohl, R. F., Erdfelder, E., Hilbig, B. E., Liebke, L., \& Stahlberg, D. (2013). Effort reduction after self-control depletion: The role of cognitive resources in use of simple heuristics. Journal of Cognitive Psychology, 25, 267-276. doi: 10.1080/20445911.2012.758101 السلسلسلس

Pittarello, A., Leib, M., Gordon-Hecker, T., \& Shalvi, S. (2015). Justifications shape ethical blind spots. Psychological Science, 26,

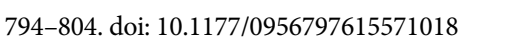

Rand, D. G. , Peysakhovich, A. , Kraft-Todd, G. T. , Newman, G. E. , Wurzbacher, O. , \& Nowak, M. A., ... Greene, J. D. (2014). Social heuristics shape intuitive cooperation. Nature Communications, 5. السلسلسل|

Schmeichel, B. J., Vohs, K. D., \& Baumeister, R. F. (2003). Intellectual performance and ego depletion: Role of the self in logical reasoning and other information processing. Journal of Personality and Social Psychology, 85, 33-36. doi: 10.1037/0022-3514.85.1.33 السلسلسلة

Shalvi, S., Eldar, O., \& Bereby-Meyer, Y. (2012). Honesty requires time (and lack of justifications). Psychological Science, 23, 1264-1270. doi: 10.1177/0956797612443835 البلسلس

Shi, R., \& Chang, L. (2019). Intuition-based prosociality: Thinking based on social heuristics hypothesis. Advances in Psychological Science, 27, 1468-1477. doi: 10.3724/SP.J.1042.2019.01468 المالسلسلس

Speer, S. P. H., Smidts, A., Boksem, M. A. S. (2020). Cognitive control increases honesty in cheaters but cheating in those who are honest. Proceedings of the National Academy of Sciences, 117, 19080-19091. doi: 10.1073/pnas.2003480117 المالسلس

Spence, S. A., Farrow, T. F., Herford, A. E., Wilkinson, I. D., Zheng, Y., \& Woodruff, P. W. (2001). Behavioural and functional anatomical correlates of deception in humans. Neuroreport, 12, 2849-2853. doi:

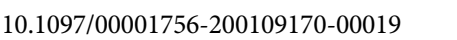

Suchotzki, K., Verschuere, B., Van Bockstaele, B., Ben-Shakhar, G., \& Crombez, G. (2017). Lying takes time: A meta-analysis on reaction time measures of deception. Psychological Bulletin, 143, 428-453. doi: $10.1037 /$ bul0000087 سلس

Tabatabaeian, M., Dale, R., \& Duran, N. D. (2015). Self-serving dishonest decisions can show facilitated cognitive dynamics. Cognitive Processing, 16, 291-300. doi: 10.1007/s10339-015-0660-6 المسلس

Tice, D. M., Baumeister, R. F., Shmueli, D., \& Muraven, M. (2007). Restoring the self: Positive affect helps improve self-regulation following ego depletion. Journal of Experimental Social Psychology, 43, 379-384. doi: 10.1016/j.jesp.2006.05.007 السلسلس

Tinghög, G., Andersson, D., Bonn, C., Johannesson, M., Kirchler, M., Koppel, L., \& Västffäll, D. (2016). Intuition and moral decision- 
making. The effect of time pressure and cognitive load on moral judgment and altruistic behavior. PLoS One, 11, e0164012. doi:

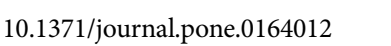

Van Dillen, L. F., Papies, E. K., \& Hofmann, W. (2013). Turning a blind eye to temptation: How cognitive load can facilitate self-regulation. Journal of Personality and Social Psychology, 104, 427-443. doi:

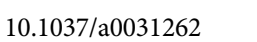

Verschuere, B., Köbis, N. C., Bereby-Meyer, Y., Rand, D., \& Shalvi, S. (2018). Taxing the brain to uncover lying? Meta-analyzing the effect of imposing cognitive load on the reaction-time costs of lying. Journal of Applied Research in Memory and Cognition, 7, 462-469. doi: 10.31219/osf.io/uqvkt لسلس

Vrij, A., Fisher, R., Mann, S., \& Leal, S. (2006). Detecting deception by manipulating cognitive load. Trends in Cognitive Sciences, 10, 141-142. doi: 10.1016/j.tics.2006.02.003 الس

Vrij, A., Fisher, R., Mann, S., \& Leal, S. (2008). A cognitive load approach to lie detection. Journal of Investigative Psychology and Offender Profiling, 5(1-2), 39-43. doi: 10.1002/jip.82 السلسلسلس

Vrij, A., Granhag, P. A., Mann, S., \& Leal, S. (2011). Outsmarting the liars: Toward a cognitive lie detection approach. Current Directions in Psychological Science, 20, 28-32. doi: 10.1177/0963721410391245 المالسلسل

Wagner, D. D., \& Heatherton, T. F. (2012). Self-regulatory depletion increases emotional reactivity in the amygdala. Social Cognitive and Affective Neuroscience, 8, 410-417.doi: 10.1093/scan/nss082 السلسلس

Wagner, D. T., Barnes, C. M., Lim, V. K., \& Ferris, D. L. (2012). Lost sleep and cyber loafing: Evidence from the laboratory and a day light saving time quasi-experiment. Journal of Applied Psychology, 97, 1068-1076. doi: 10.1037/a0027557 المالسلس
Walczyk, J. J., Harris, L. L., Duck, T. K., \& Mulay, D. (2014). A socialcognitive framework for understanding serious lies: Activationdecision-construction-action theory. New Ideas in Psychology, 34, 22-36. doi: 10.1016/j.newideapsych.2014.03.001 المالسلس

Welsh, D. T., Mai, K. M., Ellis, A. P., \& Christian, M. S. (2018). Overcoming the effects of sleep deprivation on unethical behavior: An extension of integrated self-control theory. Journal of Experimental Social Psychology, 76, 142-154. doi: 10.1016/j. jesp.2018.01.007 布

Wu, H., Hu, X., \& Fu, G. (2009). Does willingness affect the N2-P3 effect of deceptive and honest responses? Neuroscience Letters, 467, 63-66. doi: 10.1016/j.neulet.2009.10.002 Wلس

Wu, S., Peng, M., Mei, H., \& Shang, X. (2019). Unwilling but not unable to control: Ego depletion increases effortful dishonesty with material rewards. Scandinavian Journal of Psychology, 60, 189-194.doi: 10.1111/sjop.12526 إس

Zhong, C. B. (2011). The ethical dangers of deliberative decision making. Administrative Science Quarterly, 56, 1-25. doi: 10.2189/ asqu.2011.56.1.001 الس الس 